\title{
Investigation on the Physical and Mental Health of College Students Based on Statistics
}

\author{
Wang Jianjian ${ }^{1, a}$, Shen Guofang ${ }^{2, b^{*}}$, Wang Zeyu ${ }^{3, c}$ \\ ${ }^{1}$ School of Automation Wuhan University of Technology, Wuhan, China \\ ${ }^{2}$ School of materials science and engineering Wuhan University of Technology, Wuhan, China \\ ${ }^{3}$ School of Automation Wuhan University of Technology, Wuhan, China
}

\begin{abstract}
Contemporary college students face pressures from employment, emotion, and academic work, so the physical and mental health of college students has gradually become the focus of social attention. Through a questionnaire survey, this paper investigates five aspects : college students'sense of physical health, physical exercise, psychological distress, stress resistance and psychological adjustment methods. College students' physical and mental health has been analyzed from the basic situation, differences in different student groups, main problems and suggestions, trying to objectively reflect the physical and mental health of college students and provide a basis for the development of college students'ideological and political education.
\end{abstract}

\section{Introduction}

The physical and mental health education of college students is an important part of the moral education in colleges and universities. Facing the increasing psychological problems of college students and the grim reality that college students'physical fitness needs to be improved, the significance of promoting college students'physical and mental health is self-evident. From the perspective of social development, it is directly related to the construction of a healthy China and the construction of a harmonious society; from the perspective of individuals and families, it is a deep guarantee for personal growth and family happiness[1].

\section{Survey Object and Method}

In this study, students from Wuhan University of Technology were selected as samples. Participants followed the principle of random sampling. 4150 formal questionnaires were issued and 3682 questionnaires were returned, covering all colleges and all grades. Among them, 3626 valid questionnaires were used for data analysis, and the actual effective recovery rate was $87.37 \%$. This paper uses SPSS data processing software to analyze the physical and mental health of college students. The analysis of differences between different student groups uses independent sample $T$ test and one-way analysis of variance, and conducts difference verification from different gender, grade, economic status, etc., in an effort to objectively reflect and show the physical and mental health of college students.

\section{Basic Physical and Mental Health}

\subsection{Sense of physical health}

The survey shows that $77.93 \%$ of college students think that their physical condition is "very healthy" and "relatively healthy", which shows that the current physical health of college students is generally good. But at the same time, $18.04 \%$ of college students think that their physical health is "normal", and $3.14 \%$ and $0.88 \%$ of college students feel that their bodies are "not very healthy" and "very unhealthy" respectively. This shows that the overall physical health of college students still needs to be further improved, and it is still an important task of college education to attach importance to college students' physical exercise and enhance their physical fitness.

\subsection{Physical exercise}

The current overall situation of college students' physical exercise is not optimistic. It is manifested by poor enthusiasm for physical exercise and fewer exercises per week. The survey shows that $40.9 \%$ of college students exercise 1-2 times a week, $37.0 \%$ of them exercise 3-4 times a week, and only $16.4 \%$ of them exercise more than 5 times a week. There are still $5.7 \%$ of college students who never exercise. It can be seen from the above data that the proportion of college students who exercise regularly is very low.

In order to further understand the overall situation of contemporary college students' physical exercise, we assign the weekly participation of college students to

ae-mail: wang1jian9jian88@whut.edu.cn, ce-mail: 1461765835@qq.com

*be-mail: 463103405@qq.com 
"never exercise", "1-2 times", "3-4 times", and "5 times or more" respectively as $0,1,2,3$, and perform mean statistics. The statistical results found that the average value of college students' weekly physical exercise is 1.641, which means that the current average of college students' weekly physical exercise is about 2-3 times. This shows that the current average number of physical exercises per week for college students is too small, and the current college students have not established the awareness of attaching importance to physical exercise, let alone forming a good habit of exercising every day.

\subsection{Psychological distress}

According to the survey, college students "occasionally have" negative emotions such as pain, anxiety, and sorrow accounted for $63.24 \%$, the highest proportion; college students "rarely have" negative emotions accounted for $15.22 \%$; college students "have almost no" negative emotions accounted for $2.65 \%$. This shows that most college students have fewer negative emotions, and most college students are emotionally healthy and stable. But at the same time, $3.2 \%$ of college students "often have" negative emotions, and $15.69 \%$ of college students "sometimes have" negative emotions. This shows that a certain proportion of college students still have bad emotions and have certain psychological distress problems.

\subsection{Compressive ability}

The ability of college students to resist stress is not only an important manifestation of their physical and mental health, but also an important factor that affects their physical and mental health, and has an important impact on their growth and development. The survey shows that $69.64 \%$ of college students think their ability to withstand stress is "very strong" and "relatively strong", and 2.98\% of college students think that their ability to withstand stress is "relatively weak" and "very weak". This shows that the current undergraduates' ability to withstand pressure is relatively good. Most college students have strong ability to withstand pressure, but there are also a small number of college students who have weak ability to withstand pressure.

\subsection{Ways of psychological adjustment}

The survey shows that when there is stress or poor mood, $43.71 \%$ of college students choose to "actively participate in recreational activities to relax their mood"; $30.12 \%$ of college students adjust their mood by "finding someone to talk to". These two methods are reasonable and rational ways to vent their emotions and adjust their psychology, which shows that most students can still adopt the correct way to adjust their own psychology. However, when there is a problem, $22.23 \%$ and $1.65 \%$ of the college students respectively choose "silent words", "smoking, drinking, skipping meals, or overeating", which will cause harm to the body. This shows that some college students still adopt wrong and irrational adjustment methods when they have negative emotions and psychological distress.

When asked "If you think you have a mental problem, would you go for mental health consultation?", only $8.9 \%$ and $43.4 \%$ of college students chose "will" and "maybe" respectively, and students who chose "generally not" and "absolutely not" accounted for $29.9 \%$, and $17.8 \%$ said "unsure". Psychological consultation is an important way to regulate psychology. It is normal to conduct psychological consultation when encountering psychological problems, but the proportion of college students who choose psychological consultation when they have psychological problems is very low. This shows that college students' recognition and acceptance of psychological consultation is low, and there are problems in their cognition of psychological consultation, which affects the role of psychological consultation in promoting college students' mental health.

\section{Differences in the Health of Different Groups of College Students}

In order to further explore the differences in online behaviors and health levels of different groups of students by different factors, the research team discussed different groups in terms of gender, grade, parent's education level, student cadre experience, whether or not one child is only child, and family economic status. The differences in students' health status were verified, and the results are shown in Table 1.

Table 1 Analysis of differences in physical and mental health of different groups of students $(\mathrm{N}=3626)$

\begin{tabular}{|c|c|c|c|c|c|c|c|}
\hline \multicolumn{2}{|c|}{ health condition } & indicator & $\begin{array}{l}\text { healthy } \\
\text { feeling }\end{array}$ & physical & $\begin{array}{c}\text { psychol- } \\
\text { ogical }\end{array}$ & anti-pressure & consultant \\
\hline \multirow{4}{*}{ gender } & male & 2628 & 3.887 & 3.726 & 4.169 & 4.029 & 3.226 \\
\hline & female & 998 & 3.969 & 3.421 & 4.342 & 4.181 & 3.417 \\
\hline & t-value & & -3.009 & 10.47 & -4.075 & -5.575 & -4.872 \\
\hline & $\mathrm{p}$-value & & 0.003 & 0 & 0 & 0 & 0 \\
\hline \multirow{4}{*}{ grade } & juniorp & 1848 & 3.912 & 3.671 & 4.23 & 4.056 & 3.269 \\
\hline & senior & 1778 & 3.906 & 3.611 & 4.202 & 4.086 & 3.289 \\
\hline & t-value & & 0.252 & 2.224 & 0.683 & -1.223 & -0.544 \\
\hline & p-value & & & 0.026 & & & \\
\hline \multirow{5}{*}{$\begin{array}{l}\text { father's } \\
\text { education }\end{array}$} & below & 2687 & 3.908 & 3.624 & 4.253 & 4.081 & 3.272 \\
\hline & above & 939 & 3.912 & 3.692 & 4.112 & 4.042 & 3.298 \\
\hline & t-value & & -0.111 & -2.196 & 2.962 & 1.426 & -0.654 \\
\hline & p-value & & & 0.028 & 0.003 & & \\
\hline & below & 2930 & 3.913 & 3.627 & 4.25 & 4.079 & 3.268 \\
\hline
\end{tabular}




\begin{tabular}{|c|c|c|c|c|c|c|c|}
\hline \multirow{3}{*}{$\begin{array}{l}\text { mother's } \\
\text { education }\end{array}$} & above & 690 & 3.896 & 3.706 & 4.073 & 4.036 & 3.322 \\
\hline & t-value & & 0.536 & -2.203 & 3.27 & 1.374 & -1.206 \\
\hline & p-value & & & 0.028 & 0.001 & & \\
\hline \multirow{4}{*}{ student cadre } & yes & 2193 & 3.903 & 3.69 & 4.23 & 4.077 & 3.346 \\
\hline & no & 1433 & 3.918 & 3.567 & 4.195 & 4.062 & 3.177 \\
\hline & t-value & & -0.591 & 4.422 & 0.848 & 0.582 & 4.734 \\
\hline & p-value & & & 0 & & & 0 \\
\hline \multirow{4}{*}{$\begin{array}{c}\text { only child or } \\
\text { not }\end{array}$} & yes & 1926 & 3.899 & 3.67 & 4.172 & 4.05 & 3.304 \\
\hline & no & 1700 & 3.92 & 3.609 & 4.267 & 4.094 & 3.251 \\
\hline & t-value & & -0.812 & 2.24 & -2.348 & -1.795 & 1.515 \\
\hline & $\mathrm{p}$-value & & & 0.025 & 0.019 & & 0.13 \\
\hline \multirow{5}{*}{$\begin{array}{c}\text { family } \\
\text { financial } \\
\text { status }\end{array}$} & superior & 331 & 3.912 & 3.707 & 4.094 & 4.018 & 3.45 \\
\hline & common & 2360 & 3.915 & 3.624 & 4.209 & 4.073 & 3.272 \\
\hline & difficult & 935 & 3.894 & 3.663 & 4.277 & 4.085 & 3.236 \\
\hline & F-test & & 0.26 & 1.917 & 2.913 & 1.028 & 2.708 \\
\hline & p-value & & & & & & \\
\hline \multicolumn{2}{|c|}{ aggregate } & 3626 & 3.909 & 3.642 & 4.217 & 4.071 & 4.113 \\
\hline
\end{tabular}

\subsection{Differences in health status of students of different genders}

In terms of physical health, the average value of boys was 3.887 and the average value of girls was 3.969. Girls feel healthier than boys ( $\mathrm{T}=3.009, \mathrm{P}=0.003)$. In terms of physical exercise, the average value of boys is 3.726 and the average value of girls is 3.421. The frequency of boys participating in physical exercise is much higher than that of girls $(\mathrm{T}=-10.470, \mathrm{P}=0.000)$. In terms of psychological distress, the mean value of boys was 4.169 and the mean value of girls was 4.342. Girls were more likely to suffer from psychological problems than boys $(\mathrm{T}=4.075, \mathrm{P}=0.000)$. In terms of stress resistance, the average value of boys is 4.029 and the average value of girls is 4.181. The stress resistance of girls is much higher than that of boys $(\mathrm{T}=5.575, \mathrm{P}=0.000)$. In terms of willingness to seek psychological consultation, the average value of boys was 3.226 and that of girls was 3.417. Girls are more willing to seek psychological counseling help than boys $(\mathrm{T}=4.872, \mathrm{P}=0.000)$.

\subsection{Differences in the health status of students in different grades}

In terms of physical exercise, the average value of lower grades is 3.671 , and the mean value of upper grades is 3.611. The frequency of participation of lower grade college students in physical exercise is higher than that of higher grade college students $(\mathrm{T}=-2.224, \mathrm{P}=0.026)$.

\subsection{Differences in the health status of students with different parental education levels}

In terms of physical exercise, college students with low parents' education level participate in physical exercise less frequently than college students with high parents' education level. The average value of fathers' education level below college is 3.624, and the average value of father's education level above college is 3.692.The frequency of participation in physical exercise is higher for students whose fathers have a higher education level $(\mathrm{T}=2.196, \mathrm{P}=0.028)$; the average value for mothers with an education level below college is 3.627 , and the average for mothers with an education level above college is 3.706 . Students with higher education level participate in physical exercise more frequently $(\mathrm{T}=2.203, \mathrm{P}=0.028)$.

In terms of psychological distress, students with low parental education are more susceptible to psychological problems than students with high parental education. The average father's education level below college is 4.253, and the average father's education level above college is 4.112. Students whose fathers' education level is low are more susceptible to psychological problems $(\mathrm{T}=-2.962$, $\mathrm{P}=0.003$ ); mothers are educated The average value for those with a degree below college was 4.250 , and the average for mothers with a degree of education above college was 4.073. Students whose mothers had a low degree of education were more likely to suffer from psychological problems $(\mathrm{T}=-3.270, \mathrm{P}=0.001)$.

\subsection{Student leaders experience differences in the health status of different students}

In terms of physical exercise, the average value of college students with student cadre experience is 3.690 , and the average value of college students without student cadre experience is 3.567. College students with student cadre experience participate in physical exercise much more frequently than college students without student cadre experience $(\mathrm{T}=-4.422, \quad \mathrm{P}=0.000)$. In terms of psychological adjustment methods, the average value of college students with student cadre experience is 4.149, and the average value of college students without student cadre experience is 4.059 . College students with student cadre experience are more rational in choosing psychological adjustment methods than college students without student cadre experience ( $\mathrm{T}=-2.730, \mathrm{P}=0.006)$. In terms of seeking psychological counseling help, the average value of college students with student leadership experience is 3.346 , and the average college students without student leadership experience is 3.177. This shows that college students with student leadership experience are more willing to seek psychological counseling help ( $\mathrm{T}=-4.734, \mathrm{P}=0.000$ ) than college students without student leadership experience when they encounter psychological distress. 


\subsection{Whether there are differences in the health status of only-child students}

In terms of physical exercise, the average of only-child college students is 3.670 , and the average of non-onlychild college students is 3.609 . The frequency of non-onlychild college students' participation in physical exercise is slightly lower than that of only-child college students ( $\mathrm{T}=$ $2.240, \mathrm{P}=0.025)$. In terms of psychological distress, the average value of only-child college students is 4.172 , and the average value of non-only-child college students is 4.267. College students who are not only child are more likely to suffer from psychological problems than college students who are only-child ( $\mathrm{T}=2.348, \mathrm{P}=0.019)$.

\subsection{Differences in the health status of students with different family financial status}

In terms of willingness to seek psychological counseling, the average value of college students with superior family financial status is 3.450 , and the average value of college students with difficult family economic status is 3.236. Students with superior family economic status are more willing to seek psychological counseling help than students with difficult family economic status $(\mathrm{T}=-2.708$, $\mathrm{P}=0.029$ ).

\section{Main Issues and Suggestions}

The physical and mental health of college students is generally good. Most of the students have good physical health, have less psychological distress, and have strong ability to withstand stress. They can choose a reasonable way to adjust their mentality, but the survey also reflects some issues worth of attention.

\subsection{The main problems}

College students don't pay enough attention to physical exercise. The average number of physical exercises per week is 1.64.The average number of college students doing physical exercise is about 2-3 times per week. The overall enthusiasm for physical exercise is relatively poor, and the number of exercises per week is relatively small.

The proportion of negative emotions is relatively high. The proportions of "always", "often" and "occasionally" having negative emotions are all higher than the national value. If such students endure negative emotions for a long time without effective adjustment and help, it will cause certain harm to their body and mind.

Some college students' psychological adjustment methods are unscientific. Most students in our school will choose positive adjustment methods when they encounter psychological distress, but there are still $26.17 \%$ of students who choose negative adjustment method such as "silence", "smoking, drinking, skipping meals, or overeating" when encountering psychological problems, $29.9 \%$ of the students still choose "generally not" and "absolutely not" to seek psychological counseling, and $17.8 \%$ said they are "unsure". This shows that current college students still lack understanding and trust in mental health consultation.

\subsection{Countermeasures and suggestions}

First, we should strengthen the physical and mental health education of college students. We should pay attention to the mental health of college students, establish a sound monitoring and evaluation mechanism for college students' mental health, and keep abreast of the mental health of college students in a timely manner. We should increase the degree of attention to the emotional health of college students and popularize mental health knowledge so that college students have a correct and in-depth understanding of mental health knowledge, institutions and counseling. We should pay attention to physical exercise, enhance the physical fitness of college students, and help college students to establish and strengthen the awareness of attaching importance to physical exercise. We should guide college students to master the methods of selfphysical exercise through various forms of exercise exercises, improve physical fitness and resolve some psychological problems [2].

Second, we should guide college students to master the methods of self-physical exercise. The difference analysis find that it is necessary to focus on the characteristics of different groups of students to improve the pertinence of education. We should establish information databases for different groups, formulate scientific and reasonable assistance programs, monitor data and information in real time, and achieve timely feedback and effective intervention [3]. We should strengthen the attention to the physical and mental health of the female group, increase the frequency of physical exercises, and reduce their psychological distress. We should introduce physical and mental health education to senior group students and increase the frequency of physical exercise. The willingness to seek psychological counseling among girls and students with financial difficulties in families also deserves our attention, and they need to be guided to form a correct understanding and in-depth understanding of their mental health.

Third, we should enrich the ways, methods and forms of physical and mental health education for college students. We should change the concept of mental health education and integrate mental health education into practice [4]. We should add physical and mental health education courses, hold physical and mental health education lectures and relate theme activities, so that college students can master the knowledge of physical and mental health. Encouraging physical exercise has a significant role in promoting interpersonal communication, emotional management, teamwork and competition consciousness of college students [5]. The education of the physical and mental health of college students should not be limited to one point. A rich ideological and political education system should be formed, and multiple measures should be taken simultaneously, infiltrating each other, forming a joint force, and ultimately producing an overall improvement effect on ideological and political quality. 


\section{Conclusion}

At present, college students are in good physical and mental health, with a good sense of physical health and a strong sense of physical exercise, less psychological distress and strong ability to resist pressure and mental adjustment. In terms of physical health, college students are in good physical condition and attach great importance to physical exercise. In terms of mental health, college students have less negative emotions in life, generally have a certain ability to resist pressure, and can reasonably adjust their mood. However, there are still a small number of college students have not yet established the due sense of trust. We should strengthen the physical and mental health education of college students, pay attention to the physical and mental health education of different groups of college students, enrich the ways of physical and mental health education of college students.

\section{References}

1. Zhou Jing,Ma DeWen.Research on the mechanism and practice path of promoting college students' physical and mental health from the perspective of medical anthropology [J].Journal of Southwest Minzu University(Humanities and Social Science),2021, 42(03):209-216.

2. GAO Jia,TIAN Hai-yan.Research on the Influence of Physical Education on Impoverished College Students for Physical and Mental Health[J].Journal of Shenyang Institute of Engineering ( Social Sciences),2020,16(01):138-144.

3. QI Da-lu, LING Kun.The Influence of Exercise Intervention and Health Education on the Physical Health of College Students with Different Body Forms[J].Journal of Harbin Sport University,2018, 36(01):85-91.

4. Liu MengDi,Xue YuQin.Mental health education of college students in the new era: problems and countermeasures [J].Journal of Liaoning Educational Administration Institute,2021,38(01):35-40.

5. Guo LianXin,Sun MengJie.Exploration of the Promotion of Physical Exercise in Psychological Health Development Pathway of CollegeStudents[J]. HEI LONGJIANG SCIENCE,2021,12(01):148-149. 